\title{
Simultaneous extensions of polyadic groups
}

\section{VASILE POP}

\section{ABSTRACT.}

The reduction of two polyadic groups of arbitrary arity to the same group was studied by I. Corovei, I. Purdea and V. Pop. In this paper we give necessary and sufficient conditions under which two polyadic groups of $(m+1)$ and $(n+1)$ arity can be extended to the same $(k+1)$-group, where $k$ is multiple of $m$ and $n$.

\section{REFERENCES}

[1] Corovei, I., Purdea, I., The reduction of $(m+1)$-groups and its extensions to the same group, Preprint sem. of algebra, Babeş-Bolyai Univ., 5 (1988), 63-68

[2] Dörnte, W., Untersuchungen über einen verallgemeinderten Gruppenbegrieff, Math. Z., 29 (1929), 1-19

[3] Dudek, W. A. and Michalski, J., On a generalization of Hosszu Theorem, Dem. Math., 3 (1982), 783-805

[4] Hosszu, M., On explicit form of n-group operation, Publ. Math. Debrecen, 10 (1963), 88-92

[5] Pop, V., Reduction of two polyadic groups to a group, Aut. Comput. Appl. Math., 14 (2005), No. 1, 9-16

Department of MATHEMATics

TECHNICAL UNIVERSITY OF CLUJ-NAPOCA

Memorandumului 28, 400114 Cluj-Napoca, Romania

E-mail address: vasile.pop@math.utcluj.ro

Received: 22.10.2013; In revised form: 09.09.2014; Accepted: 20.10.2010

2010 Mathematics Subject Classification. 20N15.

Key words and phrases. $n$-groups, extension of n-groups, simultaneous reducible groups. 